\section{A path to full-service contracting with general practitioners under National Health Insurance}

To the Editor: National Health Insurance (NHI) is important in South Africa (SA). On 27 November 2013, during a lecture at the University of the Witwatersrand, the National Minister of Health spoke about the 'Americanisation' of healthcare. In discussing service contracts for general practitioners (GPs), he was open but cautious: 'How will we monitor them?' There is a perception that GPs are poorly equipped and badly trained, and will limit patient access when they are faced with high volumes. There is also concern that the current public service will be 'destroyed' by competition with GPs.

'Americanisation' is indeed evident in SA, with hospital specialist claims having increased from $35.3 \%$ in 1992 to $60 \%$ in 2012. The GP's share declined from $11.5 \%$ in 1992 to $6.3 \%$ in $2012 .^{[1,2]}$ The population is also becoming 'Americanised' in terms of their expectations for specialist care. The benefits of a strong primary care service have been abundantly evident for a while. Primary care physicians reduce mortality compared with other specialists. Family physicians offer more easily accessed services at a lower cost, with fewer visits and fewer prescriptions. ${ }^{[3]}$ Many criticise the UK's National Health Service (NHS) for perceived poorer quality compared with services offered in the USA, but fail to see the social injustices of the latter. This is the challenge in SA: to achieve the best society-wide outcome for health spend. I support the Minister in his crusade to achieve that.

What counts in strong primary care is a combination of universal financial coverage, low or no co-payment, an equitable distribution of resources (or attempts at equitable distribution), and comprehensiveness of service. These produce greater first-contact access/use, better person-focused care over time, an expanded range of services, and better co-ordination of care ${ }^{[3]}$ This is the missing element in SA's present primary care system, as nurses 'push queues. ${ }^{[4]}$ Patients either bypass 'nurse-driven' clinics to go to hospitals, or visit GPs. Almost half of the out-of-pocket expenditure of R30 billion by South Africans in 2009 was for private GPs. ${ }^{[5]}$ Health professionals do not want to work in public clinics because of poor working conditions and poor career paths. ${ }^{[6]}$ The Green Paper on $\mathrm{NHI}^{[7]}$ has usefully spoken of a capitated primary care system where GPs are included as providers, yet the National Department of Health seems equivocal about them, with GPs facing mistrust and misrepresentation.

GPs in SA appear willing to provide services at almost the same prices as the Johannesburg Health District, the largest metropolitan health district in SA. ${ }^{[8]}$ The Minister should consider starting implementation of NHI with re-assembling the primary healthcare (PHC) service both public and private - into one robust 'public' service with strong regulatory oversight. NHI funds appear to be unspent, and government could start contracting with GPs in pilots on this basis. GPs could be asked to take on a defined population of say 10000 people in pilot districts and to service patients from this population in their own premises. They would, of course, add nurses to their teams. GPs could implement the PHC outreach programme with community health workers and task shifting, overseen by GPs themselves, and would respond to utilisation risk with strong preventive-promotive efforts and better practice management, rather than limiting access. ${ }^{[8]}$ As part of the public sector, these GPs should be subsidised for laboratory tests according to National Health Laboratory Service prices, and permitted to buy drugs according to a state-determined extended PHC formulary, or directly from contracted companies or wholesalers in line with on the State tenders. Grants for facilities and information technology should receive consideration. A broad-based black economic empowerment process could guide all contracting and procurement. The NHS in the UK was implemented in a similar simple manner in the late 1940s, with just one contract signed per GP upon entering practice, before the Labour government implemented performance management in the 1990s.

How would GPs be monitored? This could be done in the same way as in the current public service. Accountability can be made stronger with a contract that can be terminated on non-performance, and especially in the case of fraudulent use of drugs/laboratory tests. Strong performance management is needed, but what is not necessary is a slew of worthless indicators. The focus should rather be on outcomes. A third of the capitation should be at risk, based simply on one to four indicators in each of the following categories: Millennium Development Goals; clinical disease progression; patient behaviour change; and patient satisfaction (especially in relation to waiting times). Professionalism and peer review (as part of practice-based mandatory postgraduate training in family medicine) need to be built in as part of the regulatory approach in the contracting process.

The two big risks to capitation are utilisation and referrals. Pilots should test these and other important parameters such as demographic disease profiles, costs of medicines and materials, optimal staff mix, training, group practice, performance management and out-of-pocket expenditure. There are enough GPs in SA: 5000 (of the 10000 practising) could cover the country's needs. 
The government should reward early adopters of this suggested re-engineering of PHC and incentivise GPs to later manage the overall cost spiral of specialist-hospital referrals.

Government needs to move quickly to remove the referee-player conflict by setting up roles separately in pilot districts. Current facilities need to be strengthened to function as decentralised, independent providers (perhaps as community health centre-clinic complexes) and respond to patient needs, as they compete with GP providers. Competition will prove healthy. The current district health management should focus on public health strategy, programmes and outcomes, while the Office for Standards Compliance checks on quality and outcomes. There is even a role for current medical administrators, who might be subcontracted by the NHI to manage provider contracts and fee-for-service care at district level and account to the District Health Authority.

With an election coming up, these are the kind of debates we should be having.

\section{Shabir Moosa}

Department of Family Medicine, Johannesburg Health District, and Faculty of Health Sciences, University of the Witwatersrand, Johannesburg, South Africa

shabir@drmoosa.co.za

1. Council of Medical Schemes. CMS Annual Report 1992-1993. Pretoria: CMS, 1993. 2. Council of Medical Schemes. CMS Annual Report 2012-2013. Pretoria: CMS, 2013.

3. Starfield B. Primary care: An increasingly important contributor to effectiveness, equity, and efficiency of health services. SESPAS report 2012. Gac Sanit 2012;26(5):25-31. [http://dx.doi.org/10.1016/j. gaceta.2011.10.009]

4. Moosa S, Gibbs A. A focus group study of primary health care in Johannesburg Health District, South Africa: 'We are just pushing numbers'. S Afr Fam Pract 2014 (in press).

5. McIntyre D. Private sector involvement in funding and providing health services in South Africa: Implications for equity and access to health care. Harare: Equinet, 2010.

6. Moosa S, Wojczewski S, Hoffman K, et al. Why there is an inverse primary-care law in Africa. Lancet 6. Moosa S, Wojczewski S, Hoffman K, et al. Why there is an inverse primary-care law in A
Global Health 2013;1(6):e332-e333. [http://dx.doi.org/10.1016/S2214-109X(13)70119-0]

Global Health 2013;1(6):e332-e333. [http://dx.dol.org/10.1016/S2214-109X(13)70119-0]
7. National Department of Health. National Health Insurance in South Africa. Pretoria: NDoH, 2011

7. National Department of Health. National Health Insurance in South Africa. Pretoria: NDoH, 2011.
8. Moosa S, Luiz J, Carmichael T. Introducing a national health insurance system in South Africa: A general practitioner's bottom-up approach to costing. S Afr Med J 2012;102(10):794-797. [http:// dx.doi.org/10.7196/SAMJ.6072]

S Afr Med J 2014;104(3):155-156. DOI:10.7196/SAMJ.7719 